\title{
A prospective observational study involving three fixed infusion regimens of phenylephrine for hemodynamic support during spinal anaesthesia for caesarian delivery
}

\author{
Aymen Masood $^{1}$, Ajaiz Rasool ${ }^{2}$, Aabid Hussain Mir ${ }^{1 *}$, Waqurl Neesa ${ }^{3}$, Ayaz Farooqi ${ }^{3}$
}

\author{
${ }^{1}$ Department of Anaesthesiology and Critical Care, SKIMS, Soura, Srinagar, India \\ ${ }^{2}$ Department of Anaesthesiology and Critical Care, Sher-i-Kashmir Institute of Medical Sciences, SKIMS Soura \\ Srinagar Kashmir India \\ ${ }^{3}$ Department of Anaesthesiology and Critical Care, Gynaecological and Obstetrical Anesthesia, SKIMS, Soura, \\ Srinagar, India
}

Received: 17 March 2019

Accepted: 04 May 2019

\section{*Correspondence:}

Dr. Aabid Hussain Mir,

E-mail: meeraabid111@gmail.com

Copyright: () the author(s), publisher and licensee Medip Academy. This is an open-access article distributed under the terms of the Creative Commons Attribution Non-Commercial License, which permits unrestricted non-commercial use, distribution, and reproduction in any medium, provided the original work is properly cited.

\section{ABSTRACT}

Background: Spinal anaesthesia used in caesarian section is associated with hypotension which can have maternal and fetal side effects. To determine the efficacy and ideal dosing of Phenylephrine in attenuating the hypotensive episodes during caesarean section under spinal anaesthesia.

Methods: 100 patients were allocated to four groups, placebo group (PE 0) and 3 fixed phenylephrine infusion regimens, phenylephrine $25 \mu \mathrm{g} / \mathrm{min}^{-1}$ (PE 25), phenylephrine $50 \mu \mathrm{g} / \mathrm{min}^{-1}$ (PE 50), and phenylephrine $75 \mu \mathrm{g} / \mathrm{min}^{-1}$ (PE 75). Blood pressure, heart rate were noted among primary variables and fetal parameters like umbilical blood $\mathrm{pH}$ and lactate were recorded as secondary parameters.

Results: There was a significant reduction in heart rate with increasing the infusion dosage of phenylephrine, with a mean of 86.8 beats/min at the end of procedure in placebo group and 69.4 beats/min in $75 \mu \mathrm{g}$ group (p value $<0.001$ ). There was significant statistical difference among systolic blood pressure in the four groups after 7 min of the procedure and $\mathrm{p}$-value of $<0.05$ with better attenuation of hypotension in infusion groups as compared to placebo. Similarly there was significant statistical difference in diastolic blood pressure among the four groups after 8 min of the procedure with $\mathrm{p}$ values $<0.05$.

Conclusions: Prophylactic phenylephrine infusions reduced the incidence and severity of maternal pre-delivery hypotension. Among the fixed rate phenylephrine infusion regimens investigated, infusion rates of $50 \mu \mathrm{g} / \mathrm{min}^{-1}$ were associated with greater maternal hemodynamic stability compared with 25 and $75 \mu \mathrm{g} / \mathrm{min}^{-1}$, with minimal side effects and intervention.

Keywords: Caesarian section, Hypotension, Phenylephrine, Spinal anesthesia, Vasopressor

\section{INTRODUCTION}

Most of the patients undergoing caesarean delivery under spinal or epidural anaesthesia. ${ }^{1}$ The sympathectomy resulting from the neuraxial blockade is exaggerated by the physiological changes of pregnancy and puerperium, leading to hypotension in as much as $55 \%-90 \%$ of the mothers receiving spinal anaesthesia for caesarean section. $^{2}$ Holmes et al, and Lee et al, indicated that the compression of the vena cava by gravid uterus impeded the venous return and caused hypotension. ${ }^{3,4}$ Marx postulated that the subarachnoid block resulted in venous 
pooling of blood in lower legs, leading to decreased venous return and reduced cardiac output. ${ }^{5}$

Systolic hypotension more than $20-30 \%$ of the baseline blood pressure can lead to maternal low perfusion pressure, manifested as nausea-vomiting, dizziness, low consciousness, utero-placental hypo-perfusion with fetal hypoxia and acidosis. ${ }^{6}$ There are various measures to decrease the incidence and severity of hypotension which include left uterine displacement, intravenous fluid administration and the liberal use of vasopressors to prevent and treat hypotension. Phenylephrine is a selective $\alpha 1$ receptor agonist and $\beta$ agonist action is only seen at much higher dose. ${ }^{7}$ It is frequently used in obstetric anaesthesia to counteract the hypotension after Spinal Anaesthesia due to marked arterial vasoconstriction caused by its $\alpha 1$ agonist action.

The primary outcome of this study was to evaluate changes in heart rate and blood pressure post spinal block and the ideal dosing of the phenylephrine infusion which is best in attenuating episodes of hypotension and bradycardia, additional boluses of phenylephrine required and any episodes of hypertension with fixed dose infusions. The secondary outcomes were onset and level of block, APGAR score, fetal $\mathrm{pH}$ and fetal lactate levels.

\section{METHODS}

This prospective observational study was conducted in Gynecology and Obstetrics division of Department of Anaesthesiology and critical care of a tertiary care hospital and 100 pregnant women of American society of Anesthesiologists physical status I and II with singleton gestation at a gestational age of $\geq 36$ weeks were included.

Pregnant patients who were in labor, with diabetes mellitus, hypertension or cardiac disease, obese with body mass index $>45 \mathrm{~kg} . \mathrm{m}^{-2}$ or on drugs like monoamine oxidase inhibitors were excluded from the study.

After shifting the patient to operating room baseline arterial blood pressure and heart rate (HR) was measured in the supine position with left uterine displacement. Baseline systolic blood pressure (SBP) was determined by calculating mean of three consecutive SBP measurements taken 5 minutes apart when the patient was left undisturbed. Baseline SBP was used to determine the acceptable range of $\pm 20 \%$ outside of which a physician intervention was indicated by study protocol.

Patients were allocated to a placebo group (PE 0) or 3 fixed phenylephrine infusion regimens: phenylephrine 25 $\mu \mathrm{g} / \mathrm{min}^{-1}$ (PE 25), phenylephrine $50 \mu \mathrm{g} / \mathrm{min}^{-1}$ (PE 50), phenylephrine $75 \mu \mathrm{g} / \mathrm{min}-1$ (PE 75). The infusions were given in identical $50 \mathrm{~mL}$ syringes containing normal saline (PE 0), or phenylephrine at a concentration of 25 , $50,75 \mu \mathrm{g} / \mathrm{mL}^{-1}$ by a physician involved in the study.
Standard noninvasive monitoring was applied, including pulse oximetry, electrocardiography, and noninvasive blood pressure. Spinal anaesthesia was performed in the sitting position at the L3-4 or L4-5 interspace using a 27gauge Quinke's spinal needle with fentanyl $25 \mu \mathrm{g}(0.5$ $\mathrm{ml}$ ) and $0.5 \%$ hyperbaric bupivacaine $2.5 \mathrm{~mL}$ (total volume $3 \mathrm{~mL}$ ). Immediately after the injection of the intrathecal medication, infusion of study drug was started at $60 \mathrm{~mL} . \mathrm{h}-1$ in combination with a fluid co-load. Study drug infusion was connected to the most distal drug administration port and a pressurized $1 \mathrm{~L}$ bag of lactated Ringer solution was started, with the aim of administering at least $2 \mathrm{~L}$ before delivery of the baby. Patients were immediately laid supine with left uterine displacement. Noninvasive blood pressure readings were taken every minute for the first 10 minutes after spinal injection and 2.5 minutes thereafter. After delivery, 2.5 unit oxytocin was administered intravenously as a bolus followed by an infusion over the next 2 hours (10 units in $500 \mathrm{~mL}$ lactated Ringer solution). The study drug was infused until 10 minutes after delivery.

Physician interventions were triggered by a change in any of the following hemodynamic variables: a decrease in SBP $>20 \%$ of baseline or SBP $<90 \mathrm{mmHg}$ treated by administering a $100 \mu \mathrm{g}$ bolus of phenylephrine, an increase in the SBP to more than $20 \%$ of baseline treated by stopping the infusion. Infusions were restarted when the SBP decreased to below the upper limit of the target range (>20\% above baseline). Glycopyrrolate $0.4 \mathrm{mg}$ was administered for bradycardia defined as $\mathrm{HR}<50$ beats/min.

The cephalad extent of the sensory block at 5, 10 and 20 minutes after placement of the spinal Anaesthesia was recorded using loss of pin prick sensation. Patients were asked to rate the severity of their nausea at 5, 10, and 15 minutes after spinal injection and at the end of the study using an 11-point verbal rating scale $(0=$ no nausea, $10=$ worst possible nausea).They were asked to report nausea occurring at any other time. Intraoperative nausea or vomiting not related to hypotension will be treated with ondansetron $4 \mathrm{mg}$ IV. Intraoperative nausea or vomiting occurring immediately before or after a $20 \%$ reduction in maternal SBP was recorded as hypotension- induced nausea or vomiting. Apgar scores at 1 and 5 minutes were recorded. Blood samples were collected from a double clamped segment of the umbilical cord for the measurement of umbilical vein blood gases.

\section{Statistical analysis}

Power of the study is $80 \%$. Data was analyzed using SPSS software. Quantitative data was expressed using mean and standard deviation while qualitative data was expressed in frequency and percentage. Qualitative data was analyzed using chi-square test. Numeric measures will be compared using student t-test. All the results are discussed at $5 \%$ level of significance. 


\section{RESULTS}

The mean age in our patients was $27.5 \pm 2.75$ years, all the four groups were comparable in age and the difference was statistically insignificant with p-value of 0.871 (Table 1). The groups were also comparable with respect to BMI with the mean BMI of $26.86 \mathrm{~kg} / \mathrm{m}^{2}$ and a standard deviation of 2.77 (Table 1). Mean Gestation age in our patients was 38.3 with a standard deviation of 1.1 weeks, with no significant statistical difference among the groups (Table 1).

Table 1: Comparison of patient characteristics in study groups.

\begin{tabular}{|lllll|l|}
\hline Patient characteristics & PE 0 $(n=25)$ & PE 25 $(n=25)$ & PE 50 $(n=25)$ & PE 75 (n=25) & P-value \\
\hline Age (years) & $27.7 \pm 2.7$ & $27.8 \pm 2.8$ & $27.2 \pm 2.7$ & $27.4 \pm 2.9$ & 0.871 \\
\hline Body mass index $\left(\mathrm{kg} / \mathrm{m}^{-2}\right)$ & $25.1 \pm 2.9$ & $26.0 \pm 2.7$ & $27.6 \pm 2.1$ & $26.7 \pm 2.6$ & 0.56 \\
\hline Gestational age (weeks) & 38 & 38 & 38 & 39 & 0.737 \\
\hline
\end{tabular}

Value expressed as mean \pm SD, ASA-PS: American society of anesthesiologist's physical status, SD: standard deviation

Table 2: Comparison of intra-operative variables in study groups.

\begin{tabular}{|llllll|}
\hline Patient characteristics & PE $0(n=25)$ & PE 25 $(n=25)$ & PE 50 $(n=25)$ & PE 75 (n=25) & P-value \\
\hline Onset of block $(\mathrm{min})$ & $9.2 \pm 1.4$ & $9.1 \pm 1.3$ & $9.2 \pm 1.4$ & $9.3 \pm 1.4$ & 0.992 \\
\hline EBL $(\mathrm{mL})$ & $662 \pm 43.9$ & $654 \pm 37.9$ & $654 \pm 43.1$ & $648 \pm 42.0$ & 0.734 \\
\hline I.D time & $5.06 \pm 0.79$ & $5.14 \pm 0.83$ & $5.12 \pm 0.84$ & $5.08 \pm 0.78$ & 0.989 \\
\hline U.D time & $2.4 \pm 0.6$ & $2.8 \pm 0.5$ & $2.7 \pm 0.4$ & $2.8 \pm 0.5$ & 0.085 \\
\hline I.V. fluid infused (L) & $2.43 \pm 0.17$ & $2.49 \pm 0.05$ & $2.49 \pm 0.05$ & $2.49 \pm 0.05$ & 0.849 \\
\hline
\end{tabular}

Value expressed as mean \pm SD, ASA-PS: EBL-estimated blood loss, I.D Time- incision to delivery time, U.D time- uterine incision to delivery time

Table 3: Comparison of highest sensory level after spinal anesthesia in various study groups.

\begin{tabular}{|lllll|}
\hline \multirow{2}{*}{ Highest sensory level } & PE 0 $(\mathbf{n = 2 5})$ & PE 25 $(\mathbf{n = 2 5})$ & PE 50 $(\mathbf{n = 2 5})$ & PE 75 $(\mathbf{n = 2 5})$ \\
\hline T4 & $15(60 \%)$ & $14(56 \%)$ & $10(40 \%)$ & $12(48 \%)$ \\
\hline T5 & $2(8 \%)$ & $2(8 \%)$ & $3(12 \%)$ & $3(12 \%)$ \\
\hline T6 & $8(32 \%)$ & $9(36 \%)$ & $12(48 \%)$ & $10(40 \%)$ \\
\hline
\end{tabular}

Table 4: Means heart rate (in beats per minute) in various groups with standard deviation at different time intervals from the mean and the associated p-values.

\begin{tabular}{|lllllllll|l|}
\hline $\begin{array}{l}\text { Mean heart } \\
\text { rate (Beats per } \\
\text { minute) }\end{array}$ & Group PE 0 $(\mathbf{n = 2 5})$ & Group PE $25(\mathbf{n = 2 5})$ & Group PE 50 (n=25) & Group PE 75 (n=25) & P value \\
\hline Baseline & 92 & SD & Mean & SD & Mean & SD & Mean & SD \\
\hline 1 min & 93.4 & 7.662 & 88.5 & 5.511 & 88.9 & 7.49 & 90.2 & 7.711 & 0.617 \\
\hline 2 min & 92.9 & 4.718 & 89.1 & 6.559 & 89.2 & 5.22 & 88.4 & 7.797 & 0.484 \\
\hline 3 min & 91 & 5.017 & 88.4 & 5.811 & 87.4 & 5.748 & 87.4 & 6.555 & 0.321 \\
\hline 4 min & 90.5 & 7.593 & 87.5 & 8.115 & 86.5 & 5.486 & 86 & 5.498 & 0.209 \\
\hline 5 min & 89 & 7.748 & 86.8 & 8.373 & 84.2 & 7.025 & 83.1 & 4.957 & 0.154 \\
\hline 6 min & 87.8 & 6.12 & 86 & 5.208 & 82.4 & 4.766 & 82.1 & 4.808 & 0.092 \\
\hline 7 min & 88 & 7.761 & 85.8 & 8.382 & 81.2 & 6.403 & 79.5 & 5.131 & 0.07 \\
\hline 8 min & 88.5 & 5.384 & 86.7 & 4.85 & 79.2 & 4.896 & 77.2 & 4.677 & $0.04 *$ \\
\hline 9 min & 88.3 & 4.51 & 86.4 & 4.888 & 78.1 & 5.123 & 76.1 & 6.185 & $0.03 *$ \\
\hline 10 min & 87.6 & 5.225 & 85.8 & 5.499 & 77.1 & 4.997 & 75.1 & 7.85 & $0.01 *$ \\
\hline 12.5 min & 88 & 8.362 & 86.2 & 8.102 & 76.2 & 6.082 & 74.5 & 8.082 & $0.007 *$ \\
\hline 15 min & 87.6 & 4.686 & 86 & 7.075 & 75.1 & 5.374 & 73.2 & 5.343 & $0.004 *$ \\
\hline 17.5 min & 87.2 & 7.081 & 85.3 & 4.828 & 74 & 5.205 & 70.9 & 6.768 & $<0.001 *$ \\
\hline 20 min & 87 & 5.221 & 85.1 & 6.923 & 73.8 & 7.67 & 70.4 & 7.29 & $<0.001 *$ \\
\hline End of surgery & 86.8 & 7.636 & 84.4 & 6.611 & 73.4 & 6.975 & 69.4 & 5.819 & $<0.001 *$ \\
\hline
\end{tabular}

*-statistically significant. 
Table 5: Mean systolic blood pressure (in $\mathrm{mmHg}$ ) in various groups with standard deviation at different time intervals from the mean and the associated p-values.

\begin{tabular}{|c|c|c|c|c|c|c|c|c|c|}
\hline \multirow{2}{*}{ Mean SBP (mmHg) } & \multicolumn{2}{|c|}{ GroupPE0 (n=25) } & \multicolumn{2}{|c|}{ GroupPE25 (n=25) } & \multicolumn{2}{|c|}{ Group PE $50(n=25)$} & \multicolumn{2}{|c|}{ Group PE $75(n=25)$} & \multirow{2}{*}{$\begin{array}{l}\text { p- } \\
\text { value }\end{array}$} \\
\hline & Mean & SD & Mean & SD & Mean & SD & Mean & SD & \\
\hline Baseline & 125.8 & 6.361 & 122.4 & 8.069 & 121.1 & 5.813 & 119.3 & 7.564 & 0.031 \\
\hline At $1 \mathrm{~min}$ & 123.1 & 6.077 & 122 & 5.262 & 119.1 & 4.965 & 118.1 & 7.632 & 0.032 \\
\hline At $2 \mathrm{~min}$ & 121.2 & 4.72 & 122.1 & 6.648 & 118.2 & 4.501 & 118.1 & 6.61 & 0.020 \\
\hline At $3 \mathrm{~min}$ & 119.6 & 6.658 & 121 & 6.255 & 118 & 6.355 & 119 & 6.058 & 0.055 \\
\hline $4 \mathrm{~min}$ & 118.5 & 6.98 & 120.6 & 7.611 & 118.7 & 5.518 & 119.2 & 4.55 & 0.050 \\
\hline $5 \mathrm{~min}$ & 118.3 & 5.033 & 119.8 & 7.833 & 118.6 & 5.179 & 120.2 & 7.69 & 0.043 \\
\hline $6 \mathrm{~min}$ & 116.9 & 5.743 & 118.8 & 4.766 & 118.8 & 6.323 & 122.4 & 6.921 & 0.023 \\
\hline $7 \mathrm{~min}$ & 116.2 & 4.84 & 118.1 & 8.001 & 118.9 & 5.053 & 122.8 & 6.553 & 0.020 \\
\hline $8 \mathrm{~min}$ & 115.2 & 6.671 & 117.6 & 7.201 & 119 & 7.069 & 124.2 & 6.053 & 0.014 \\
\hline $9 \mathrm{~min}$ & 114.8 & 5.205 & 117.1 & 6.283 & 119.2 & 5.486 & 124.6 & 6.436 & 0.006 \\
\hline $10 \mathrm{~min}$ & 114.2 & 8.161 & 116.2 & 5.499 & 119.4 & 4.628 & 125.2 & 5.326 & 0.002 \\
\hline $12.5 \mathrm{~min}$ & 113.8 & 6.132 & 115.7 & 5.819 & 119.3 & 6.483 & 125.5 & 7.146 & 0.001 \\
\hline $15 \mathrm{~min}$ & 112.5 & 5.092 & 115.1 & 5.922 & 119.6 & 8.309 & 125.5 & 6.91 & $<0.001$ \\
\hline $17.5 \mathrm{~min}$ & 110 & 7.458 & 114.2 & 4.864 & 120.2 & 5.595 & 126.2 & 7.294 & $<0.001$ \\
\hline $20 \mathrm{~min}$ & 109.6 & 5.096 & 113.9 & 5.627 & 120.6 & 5.323 & 126.7 & 4.52 & $<0.001$ \\
\hline End of surgery & 108.9 & 5.127 & 113.5 & 6.674 & 120.8 & 6.741 & 127.1 & 6.86 & $<0.001$ \\
\hline
\end{tabular}

Table 6: Mean diastolic blood pressure (in $\mathrm{mmHg}$ ) in various groups with standard deviation at different time intervals from the mean and the associated p-values.

\begin{tabular}{|c|c|c|c|c|c|c|c|c|c|}
\hline \multirow{2}{*}{$\begin{array}{l}\text { Diastolic blood } \\
\text { pressure }(\mathrm{mmHg})\end{array}$} & \multicolumn{2}{|c|}{ Group PE0 (n=25) } & \multicolumn{2}{|c|}{ Group PE25 (n=25) } & \multicolumn{2}{|c|}{ Group PE50 $(n=25)$} & \multicolumn{2}{|c|}{ Group PE75 (n=25) } & \multirow{2}{*}{ p-value } \\
\hline & Mean & SD & Mean & SD & Mean & SD & Mean & SD & \\
\hline Baseline & 75.5 & 7.205 & 71.2 & 6.01 & 69.7 & 5.408 & 72.6 & 7.915 & 0.033 \\
\hline $1 \mathrm{~min}$ & 74.2 & 5.336 & 74.6 & 7.29 & 67.2 & 8.431 & 68.2 & 6.952 & 0.019 \\
\hline $2 \mathrm{~min}$ & 73.8 & 6.315 & 73.1 & 5 & 67.5 & 6.456 & 67.6 & 6.764 & 0.014 \\
\hline $3 \mathrm{~min}$ & 72.4 & 8.489 & 71.8 & 7.22 & 68.2 & 5.973 & 68.2 & 4.734 & 0.084 \\
\hline $4 \min$ & 70.5 & 7.801 & 70 & 6.994 & 68.1 & 4.507 & 68.6 & 7.445 & 0.081 \\
\hline $5 \mathrm{~min}$ & 70.1 & 6.294 & 70.5 & 5.251 & 68.5 & 7.719 & 69.5 & 7.344 & 0.071 \\
\hline $6 \min$ & 69.7 & 7.857 & 69.1 & 4.858 & 68.4 & 7.698 & 69.6 & 4.55 & 0.067 \\
\hline $7 \mathrm{~min}$ & 69.2 & 4.709 & 68.3 & 6.162 & 68.4 & 7.366 & 69.6 & 7.575 & 0.058 \\
\hline $8 \min$ & 68.7 & 5.753 & 67.4 & 5.667 & 68.5 & 4.788 & 69.8 & 4.846 & 0.005 \\
\hline $9 \mathrm{~min}$ & 68 & 6.883 & 66.4 & 4.852 & 68.7 & 6.118 & 69.4 & 5.379 & 0.043 \\
\hline $10 \mathrm{~min}$ & 67.2 & 8.37 & 67.2 & 5.546 & 68.6 & 5.898 & 70.3 & 5.691 & 0.031 \\
\hline $12.5 \mathrm{~min}$ & 66.1 & 7.813 & 66.1 & 6.803 & 68.8 & 6.225 & 72.4 & 6.66 & 0.024 \\
\hline $15 \mathrm{~min}$ & 65.2 & 6.41 & 65.2 & 7.59 & 68.7 & 4.592 & 72.2 & 6.607 & $<0.001$ \\
\hline $17.5 \mathrm{~min}$ & 62.7 & 8.311 & 62.7 & 5.796 & 68.5 & 8.437 & 71.5 & 7.653 & $<0.001$ \\
\hline $20 \mathrm{~min}$ & 62.1 & 6.441 & 62.1 & 6.919 & 68.6 & 7.831 & 71.3 & 8.335 & $<0.001$ \\
\hline End of surgery & 61.6 & 6.1 & 59.2 & 7.248 & 68.6 & 8.126 & 71.2 & 7.482 & $<0.001$ \\
\hline
\end{tabular}

Table 7: Requirement of drugs in study groups intra-operatively.

\begin{tabular}{|c|c|c|c|c|c|}
\hline Patient characteristics & $\begin{array}{l}\text { PE 0 } \\
(n=25)\end{array}$ & $\begin{array}{l}\text { PE } 25 \\
(n=25)\end{array}$ & $\begin{array}{l}\text { PE 50 } \\
(n=25)\end{array}$ & $\begin{array}{l}\text { PE } 75 \\
(n=25)\end{array}$ & P-value \\
\hline No. of patients requiring rescue dose of PE (\%) & $23(92 \%)$ & $18(72 \%)$ & $7(28 \%)$ & $4(16 \%)$ & $<0.001 *$ \\
\hline No. of patients in which infusion was stopped & $0(0 \%)$ & $0(0 \%)$ & $1(4 \%)$ & $18(72 \%)$ & $<0.001 *$ \\
\hline Mean amount of PE infused $(\mu \mathrm{g})$ & 0 & 440 & 854 & 1338 & $<0.001 *$ \\
\hline Mean total amount of PE in $\mu \mathrm{g}$ (infusion+bolus) & 160 & 532 & 882 & 1358 & $<0.001 *$ \\
\hline Total no. of patients requiring glycopyrolate & 0 & 0 & 0 & 4 & \\
\hline Total no. of doses of glycopyrrolate given & 0 & 0 & 0 & 6 & \\
\hline
\end{tabular}


Table 8: Comparison of fetal blood variables and Apgar score in different study groups.

\begin{tabular}{|c|c|c|c|c|c|c|}
\hline \multicolumn{2}{|l|}{ Patient characteristics } & PE $0(n=25)$ & PE $25(n=25)$ & PE $50(n=25)$ & PE $75(n=25)$ & P-value \\
\hline \multicolumn{2}{|l|}{ Umbilical vein $\mathrm{pH}$} & $7.34 \pm 0.06$ & $7.35 \pm 0.04$ & $7.33 \pm 0.03$ & $7.33 \pm 0.05$ & 0.231 \\
\hline \multicolumn{2}{|l|}{ Umbilical vein lactate } & $2.2 \pm 1.12$ & $1.92 \pm 0.50$ & $1.95 \pm 0.61$ & $2.47 \pm 0.97$ & 0.084 \\
\hline \multirow{2}{*}{ Apgar score at $1 \mathrm{~min}$} & 7 & $6(24 \%)$ & $6(24 \%)$ & $3(12 \%)$ & $4(16 \%)$ & \multirow{2}{*}{0.78} \\
\hline & 8 & $19(76 \%)$ & $19(76 \%)$ & $22(88 \%)$ & $21(84 \%)$ & \\
\hline Apgar score at $5 \mathrm{~min}$ & 9 & 25 & 25 & 25 & 25 & \\
\hline
\end{tabular}

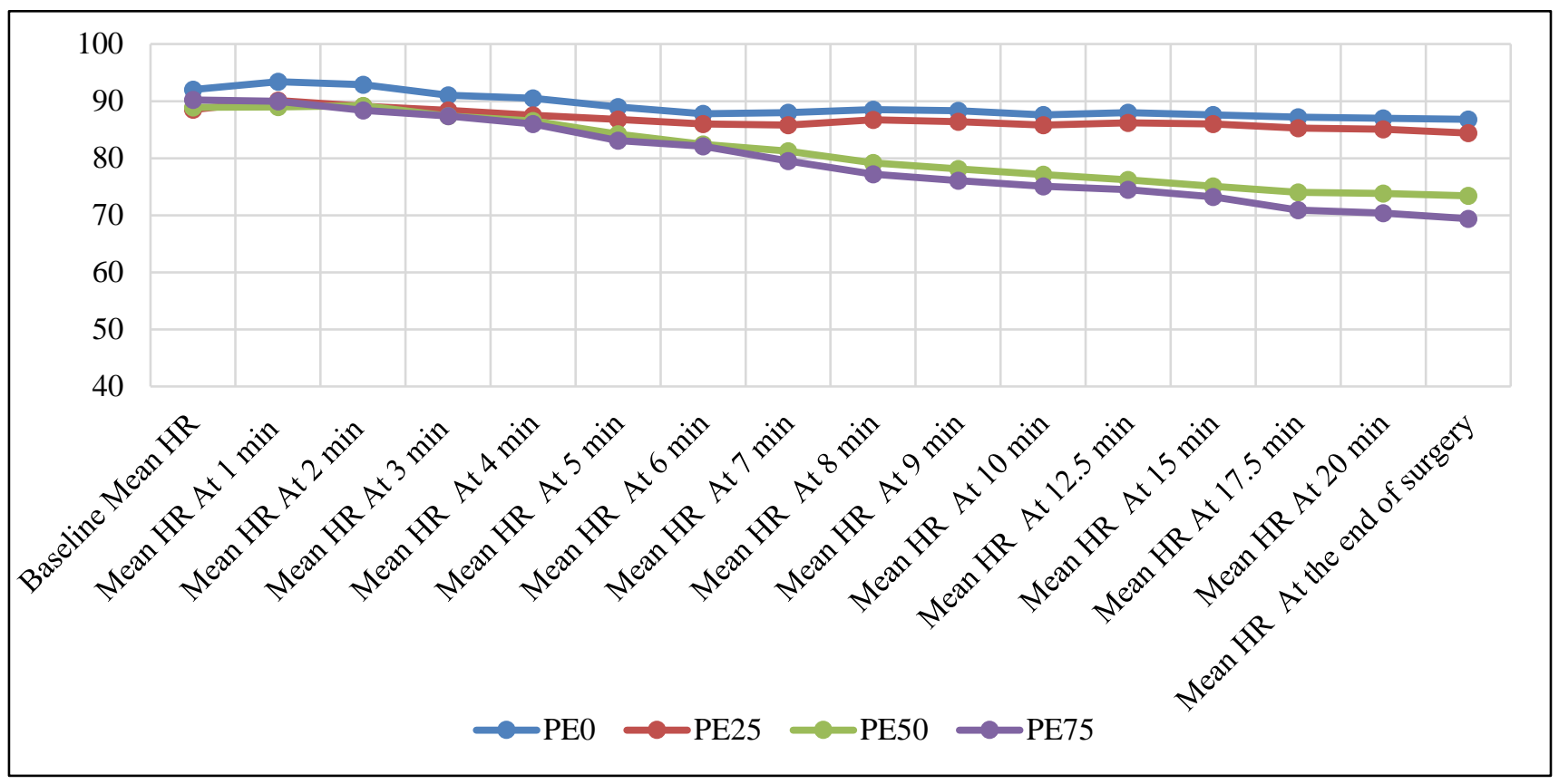

Figure 1: Comparison of mean heart rate (HR) in different groups at different study intervals.

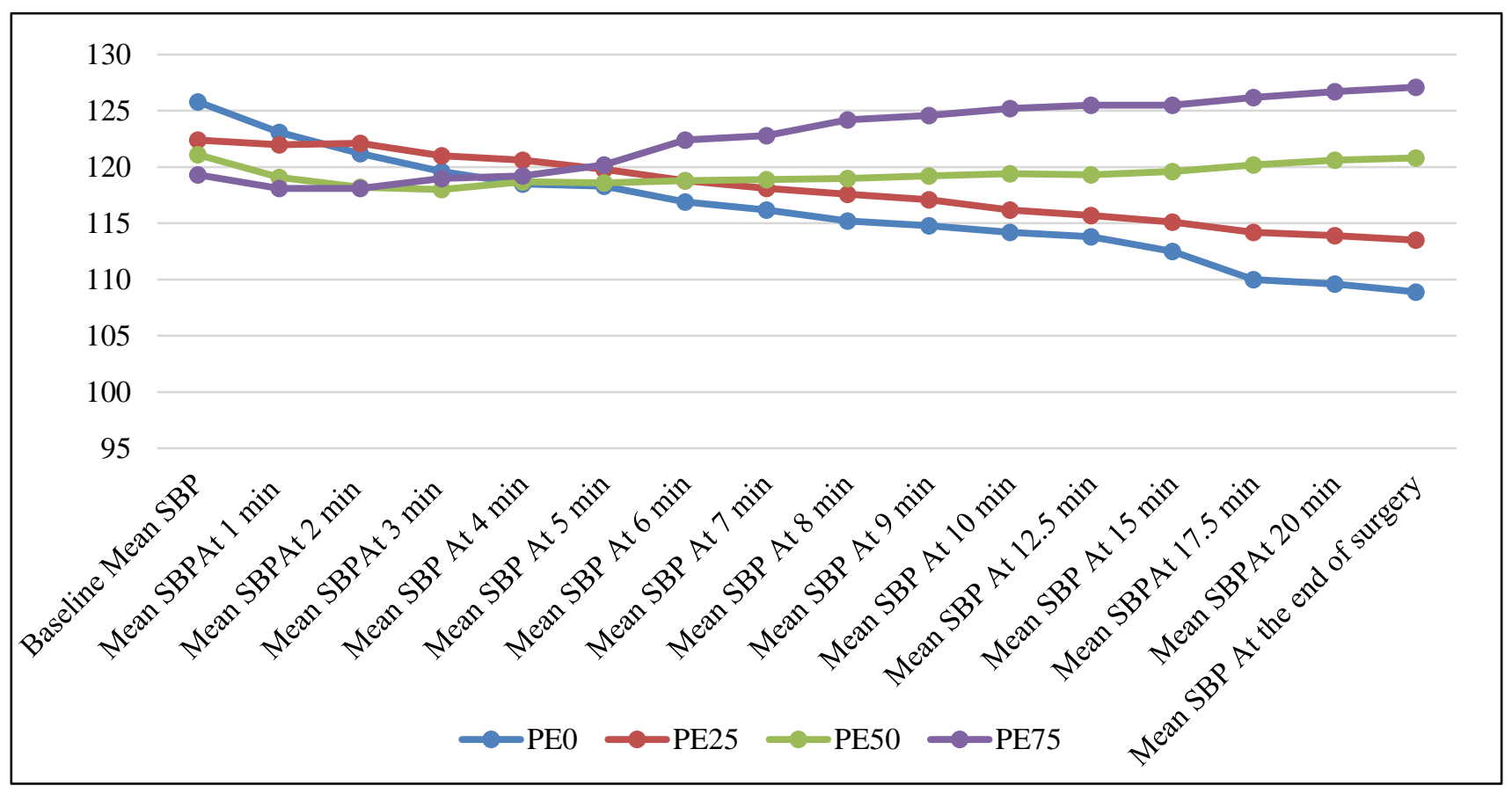

Figure 2: Comparison of mean systolic blood pressure (SBP) in different groups at different study intervals. 


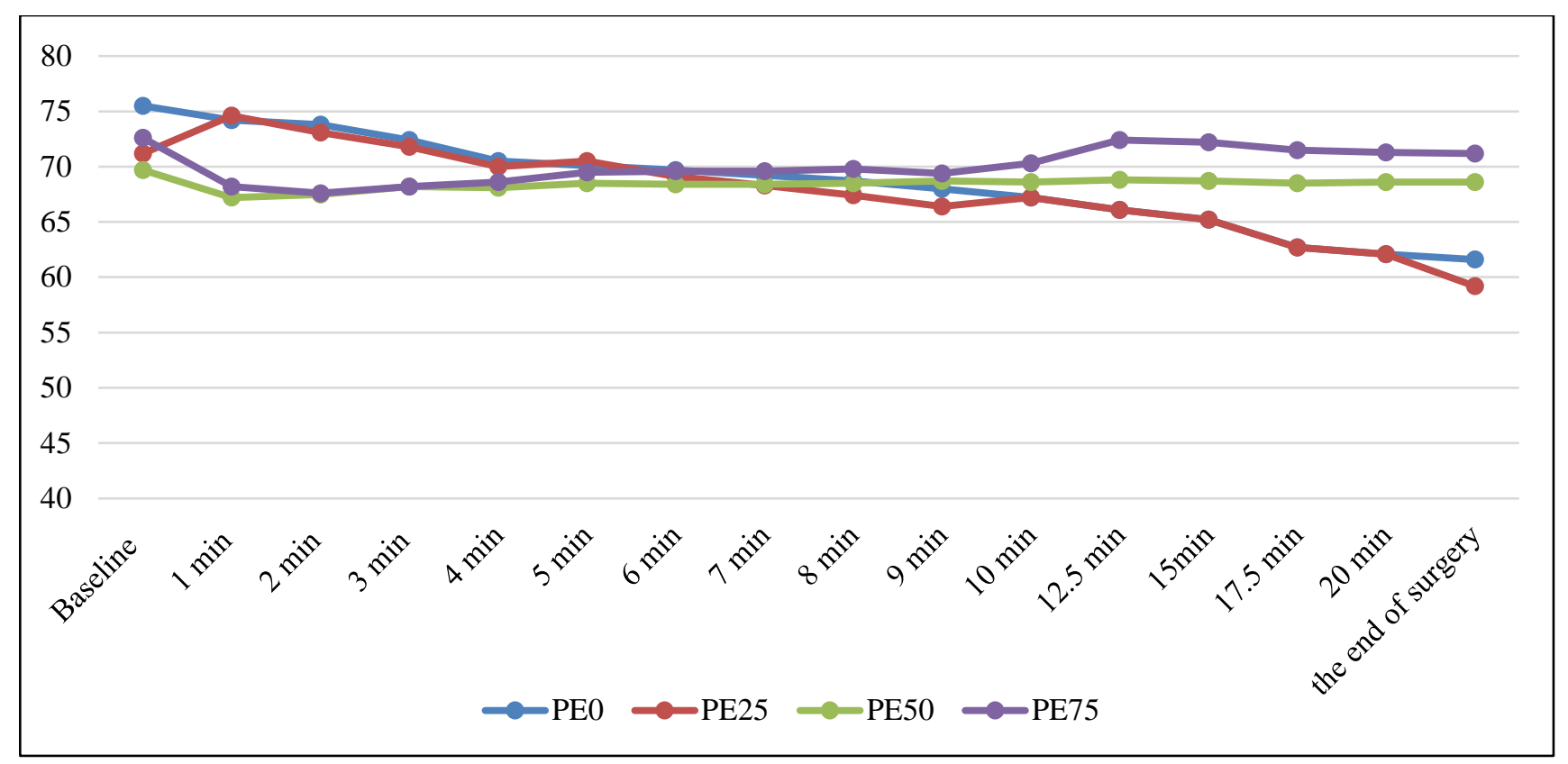

Figure 3: Comparison of mean diastolic blood pressure (DBP) in different groups at different study intervals.

The mean onset of block in this study group 9.20 minutes with SD of 1.37, the groups were comparable in terms of duration of onset of block and the difference among the groups was statistically insignificant with $\mathrm{P}$ value of 0.992 (Table 2). T4 was highest sensory level in $51 \%$ $(\mathrm{n}=51)$ patients T5 in $10 \%(\mathrm{n}=10)$ and T6 in $39 \%(\mathrm{n}=39)$ patients respectively (Table 3 ). The differences among the groups were statistically non-significant ( $\mathrm{P}$ value 0.873 ). The estimated mean blood loss in our study was $654.5 \mathrm{ml}$ with Standard Deviation of 41.2. The difference in blood loss among the different infusion groups was statistically insignificant with a p-value of 0.734 (Table 2 ). The average amount of fluid infused among the study groups was 2.47 litres with a Standard Deviation of 0.095 . The groups were comparable and the difference was statistically insignificant with p-value of 0.849 (Figure 2).

The mean heart rate at different intervals in the four groups differed significantly with the mean heart rate highest in PE0 group and lowest in PE75 group. There was a significant reduction in heart rate with increasing the infusion dosage of phenylephrine, with a mean of $86.8 / \mathrm{min}$ at the end of procedure in placebo group and $69.4 / \mathrm{min}$ in $75 \mu \mathrm{g}$ group. The difference among the groups was statistically significant with a p-value of $<0.001$ (Table 4 and Figure 1).

The systolic blood pressure was constantly on higher side in patients who received phenylephrine infusion in contrast to those who did not receive phenylephrine infusion. There was no statistically significant difference between the four groups at the start of the procedure, the mean systolic blood pressure in the PE0 group was 125.8
$\mathrm{mmHg}$, in the PE25 it was $122.4 \mathrm{mmHg}$, in the group PE50 it was $121.1 \mathrm{mmHg}$ and in the group PE75 it was 119.3 with $\mathrm{p}$-value of 0.031 . There was significant statistical difference among the four groups after $7 \mathrm{~min}$ of the procedure and p-value of $<0.05$ (Table 5, Figure 2).

The diastolic blood pressure was constantly on higher side in patients who received phenylephrine infusion in contrast to those who did not receive phenylephrine infusion. The readings were almost comparable between the four groups at the start of the procedure the mean diastolic blood pressure in the PE0 group was 75.5 $\mathrm{mmHg}$, in the PE25 it was $71.2 \mathrm{mmHg}$, in the group PE50 it was $69.7 \mathrm{mmHg}$ and in the group PE75 it was 72.6 with $p$-value of 0.033 . There was significant statistical difference among the four groups after $8 \mathrm{~min}$ of the procedure with $\mathrm{p}$ values $<0.05$ (Table 6 and Figure 3 ).

Phenylephrine bolus of $100 \mu \mathrm{g}$ was given in study subjects who developed hypotension during the course of study, hypotension was defined as systolic BP of $<80 \%$ of baseline. In this study, 92\% $(n=23)$ of patients who received saline only with no phenylephrine infusion (PE0) developed intra operative hypotension thereby requiring a phenylephrine bolus doses of $100 \mu \mathrm{g}$, whereas the number dropped to $72 \%(n=18)$ in group receiving $25 \mu \mathrm{g}$ infusion of phenylephrine (PE25). In the PE50 group $28 \%(n=7)$ patients required phenylephrine bolus doses whereas in the group PE75 only $16 \%$ patients required intervening phenylephrine bolus doses. The difference among the groups was statistically significant with p-value of $<0.001$ (Table 7).

Hypertension was defined as SBP of $>120 \%$ of the baseline, and required stopping of the phenylephrine 
infusion. In this study, none of the patients required stopping of infusion in zero phenylephrine (PE0) and 25 $\mu \mathrm{g}$ phenylephrine (PE25) groups. One patient required stoppage of infusion in $50 \mu \mathrm{g}$ group (PE50) whereas in 75 $\mu \mathrm{g}$ (PE75) group infusion had to be stopped in 18 patients with an average of 1.7 times per patient where infusion needed to be stopped with total number of stoppage of infusions equal to 32 . The difference among the groups was statistically significant with $\mathrm{p}$ value of $<0.001$ (Table 7).

The total amount of Phenylephrine infused in PE 0 Group was nil as the patients received normal saline infusions. In the PE25 group the mean amount of infused Phenylephrine was $440 \mu \mathrm{g}$ per patient with minimum of $350 \mu \mathrm{g}$ and maximum of $625 \mu \mathrm{g}$. In PE50 group it was $854 \mu \mathrm{g}$ with a maximum and minimum of 1250 and 650 $\mu \mathrm{g}$, and in PE 75 group total amount of phenylephrine infused was $1338 \mu \mathrm{g}$ with a minimum of 1050 and maximum of $1725 \mu \mathrm{g}$. The difference among the groups was statistically significant as p <0.001 (Table 7).

The mean amount of total phenylephrine (bolus+ infusion) given in PE0 group was $160 \mu \mathrm{g}$ with a minimum of $0 \mu \mathrm{g}$ and maximum of $400 \mu \mathrm{g}$. In the group PE25 the mean amount of total phenylephrine was $532 \mu \mathrm{g}$ with a minimum of $400 \mu \mathrm{g}$ and maximum of $700 \mu \mathrm{g}$, in PE50 group the total mean amount of phenylephrine was 882 $\mu \mathrm{g}$ with a minimum of $650 \mu \mathrm{g}$ and maximum of $1350 \mu \mathrm{g}$, in the group PE75 the mean total amount of phenylephrine (bolus+infusion) was $1358 \mu \mathrm{g}$ with a minimum of $1050 \mu \mathrm{g}$ and maximum of $1725 \mu \mathrm{g}$. The difference among the groups was statistically significant as p value was $<0.001$ (Table 7).

Glycopyrrolate $0.4 \mathrm{mg}$ was administered for bradycardia defined as $\mathrm{HR}<50$ beats/min. In the group PE0, PE25 and PE50 none of the patients developed significant bradycardia (HR $<50$ beats/min) therefore did not require anticholinergics. In the group PE75, four (4) patients developed bradycardia and required net six (6) doses of glycopyrrolate (Table 7).

The mean fetal umbilical vein $\mathrm{pH}$ was 7.34 with a standard deviation of 0.05 . The average fetal $\mathrm{pH}$ in PE0 group was 7.34 with a standard deviation of 0.06 , whereas in PE 25 group it was 7.35 with a standard deviation of 0.04 . The average fetal $\mathrm{pH}$ in PE50 group was 7.33 with a standard deviation of 0.03 , whereas in PE 75 group it was 7.33 with a standard deviation of 0.05 . The difference among the groups was statistically nonsignificant with p-value of 0.231 (Table 8 ).

The mean fetal umbilical vein lactate was $2.1 \pm 0.9$ $\mathrm{mmol} / \mathrm{L}$. The average umbilical vein lactate in PE0 group was 2.2 with a standard deviation of 1.12 , whereas in PE 25 group it was 1.92 with a standard deviation of 0.50 . The average umbilical vein lactate in PE50 group was 1.95 with a standard deviation of 0.61 , whereas in PE 75 group it was 2.47 with a standard deviation of 0.97 . The difference among the groups was statistically nonsignificant with p-value of 0.084 (Table 8 ).

The APGAR score in the group PE 0 at 1 min was 8 in $76 \%(n=19)$ patients , 7 in $24 \%(n=6)$ in the group PE25 group the APGAR score at 1 minute was 7 in $24 \%(n=6)$ and 19 in $76 \%(n=19)$ patients. In the group PE 50 APGAR at 1 min was 7 in $12 \%(n=3)$ patients and 8 in $88 \%(\mathrm{n}=22)$ patients. In PE75 group APGAR at 1 minute was 7 in $16 \%(n=4)$ and 8 in $84 \%(n=21)$ patients. The difference among the groups was statistically nonsignificant with p-value $=0.78$ (Table 8). The APGAR score at 5 minutes in all the patients was 9 in all the groups, there was no difference between the groups and was comparable.

\section{DISCUSSION}

Spinal anesthesia is commonly used for cesarean delivery because it avoids the risks of general anesthesia related to difficult intubation and aspiration of gastric contents. It is frequently associated with hypotension, which can have detrimental effects on the mother and neonate, including nausea, vomiting, and dizziness in the mother, as well as decreased utero-placental blood flow resulting in impaired fetal oxygenation and fetal acidosis. Various intravenous vasopressors have been tried for prevention and treatment of this hypotension.

In this study, author used fixed dose infusions of phenylephrine in three groups and compared with one who received normal saline as placebo. All the patients were monitored for onset and level of block, heart rate, blood pressure, amount of phenylephrine used, number of bolus doses given, number of times infusion stopped, APGAR score, fetal $\mathrm{pH}$ and fetal lactate levels and were analyzed statistically.

All the four groups were comparable with respect to age, BMI, gestational age, onset of block, estimated blood loss, incision to delivery time, uterine incision to delivery time and amount of fluid infused.

There was no statistically significant difference between the groups with respect to level of the sensory block; T4 was the highest sensory block in $51 \%$ of the patients followed by $\mathrm{T} 5$ and $\mathrm{T} 6$. The results were similar to Sayyid SM et al. ${ }^{8}$

The mean heart rate at different intervals in the four groups differed significantly with the mean heart rate highest in PE0 group and lowest in PE75 group. The HR in PE50 group was well controlled. The results were in concordance with Allen et al, who observed that higher phenylephrine infusion rates were associated with lower heart rates. ${ }^{9}$

The systolic and diastolic blood pressures were constantly higher throughout the procedure and at the end of the procedure in the patients receiving phenylephrine, 
the higher concentrations of phenylephrine was associated with higher systolic and diastolic blood pressures. The pressures were appropriate in PE50 group with less episodes of hypotension in terms of lesser number of phenylephrine boluses needed and lesser episodes of hypertension in terms of lesser episodes of stopping of phenylephrine infusion. Our results were in concordance with Allen et al, and Doherty et al. ${ }^{9,10}$

The requirement of phenylephrine bolus doses (thereby hypotensive episodes) was highest in the group PE0 with $92 \%$ of patients requiring a phenylephrine bolus dose of $100 \mu \mathrm{g}$, whereas the number dropped to $72 \%$ in group receiving $25 \mu \mathrm{g}$ infusion of phenylephrine and $28 \%$ in $50 \mu \mathrm{g}$ and $16 \%$ in $75 \mu \mathrm{g}$ group. Similar results were obtained by Sayyid SM et al, and Doherty et al. ${ }^{8,10}$

None of the patients required stopping of infusion in zero phenylephrine and $25 \mu \mathrm{g}$ phenylephrine groups. One patient $(4 \%)$ required stoppage of infusion in $50 \mu \mathrm{g}$ group whereas in $75 \mu \mathrm{g}$ group infusion had to be stopped in 18 patients $(72 \%)$, with total number of 33 at an average 1.7 times per patient (average 1.7 times per patient where infusion needed to be stopped), the difference among the groups was significant statistically $(\mathrm{p}=$ value $<0.001)$. Similar results were obtained by Sayyid SM et al, and Allen et al, and Stewart et al. , $9,11^{-11}$

The PE0 group received the least amount of total phenylephrine $(160 \mu \mathrm{g})$, in the group PE25 the mean amount of total phenylephrine was $532 \mu \mathrm{g}$, in PE50 group the total mean amount of phenylephrine was $882 \mu \mathrm{g}$ and in the group PE75 the mean total amount of phenylephrine was $1358 \mu \mathrm{g}$. The difference among the groups was statistically significant as p value was $<0.001$. This was in concordance with Allen et al, and Stewart et al. ${ }^{9,12}$

In the group PE0, PE25 and PE50 none of the patients developed significant bradycardia (HR $<50$ beats/min) therefore did not require anticholinergics. In the group PE75, four (4) patients developed bradycardia and required net six (6) doses of glycopyrrolate. The results were similar to Allen et al, where Glycopyrrolate was administered to 1 patient in the control group, 3 patients in group $\mathrm{PE} 25,2$ patients in group $\mathrm{PE} 75$, and 7 patients in group PE $100 .^{9}$

There was no statistically significant difference between the four groups with respect to APGAR score, fetal umbilical vein $\mathrm{pH}$, and fetal umbilical vein lactate. The results were in concordance with Allen et al, who observed that the $\mathrm{pH}$ in PE 0 group was 7.34 (7.30-7.36), in the PE25 group it was 7.35 (7.33-7.37), whereas $\mathrm{pH}$ in the group PE50 7.33 (7.32-7.35) and in group PE75 it was 7.33 (7.31-7.36) and in PE100 group $\mathrm{pH}$ was 7.33 (7.30-7.35) with a non-significant $\mathrm{p}$ value of $0.22 .{ }^{9}$ Stewart et al, also had similar results with $\mathrm{pH}$ in the group PE25 as $7.36 \pm 0.02$, in the group PE50 it was $7.35 \pm 0.03$ and in the group PE100 it was $7.35 \pm 0.03$ with a non-significant p- value. ${ }^{12}$ Sayyid SM et al, had similar results and observed that neonatal outcomes were not different between the 2 groups with phenylephrine group having UV $\mathrm{pH} 7.3 \pm 0.1$ and in saline infusion group the mean UV pH was $7.3 \pm 0.0$, with a non-significant $p$-value $(\mathrm{p}=0.60) .{ }^{8}$ Similar results were obtained by Stewart et al. ${ }^{12}$

In conclusion, the regimen of prophylactic variable rate phenylephrine infusion initially started at $50 \mu \mathrm{g} / \mathrm{kg}^{-1} / \mathrm{min}^{-1}$ combined with a crystalloid solution co-load of at least 2 liters and rescue phenylephrine boluses in parturients undergoing cesarean delivery with spinal fentanyl $25 \mu \mathrm{g}$ $(0.5 \mathrm{ml})$ and $0.5 \%$ hyperbaric bupivacaine $(2.5 \mathrm{ml})$ is more reliable than crystalloid co-load and rescue phenylephrine boluses or infusion rates of 25 or 75 $\mathrm{mcg} / \mathrm{min}$.

It is associated with fewer physician interventions, less hypotension and nausea/vomiting, minimal incidence of hypertension, as well as greater hemodynamic stability, all of which lead to increased maternal comfort. Authors did not see any adverse effects on the fetus in our study as indicated by Apgar scores and umbilical venous gases and lactate. Further work investigating more flexible regimens would be of interest and might result in the complete elimination of hypotension.

This study confirmed the clinical impression that starting a prophylactic infusion of phenylephrine immediately after the induction of spinal anesthesia for cesarean delivery would be effective at reducing the incidence, frequency, and severity of hypotension. It is noteworthy that in the PE group, despite the administration of a large total dose of phenylephrine, the fetal acid-base status and clinical condition of infants were excellent and similar in all the study groups.

Limitations of the study with large doses of phenylephrine, hypertension and maternal bradycardia can occur, reactive hypertension can be a problem and is a concern with the use of prophylactic phenylephrine infusions. Present study findings may not be applicable to clinical situations in which IV fluids are not coadministered or an alternative volume of crystalloid or colloid is administered. The simple fixed rate infusion regimen used in this study was stopped when maternal SBP exceeded the set limits and lacked titration.

\section{CONCLUSION}

Doppler sonography is an indispensable tool in In conclusion prophylactic phenylephrine infusions reduced the incidence and severity of maternal pre-delivery hypotension. Among the fixed rate phenylephrine infusion regimens investigated, infusion rates of 50 $\mu \mathrm{g} / \mathrm{min}$ were associated with greater maternal hemodynamic stability compared with 25 and $75 \mu \mathrm{g} / \mathrm{min}$, with minimal side effects and intervention. 
Funding: No funding sources

Conflict of interest: None declared

Ethical approval: The study was approved by the Institutional Ethics Committee

\section{REFERENCES}

1. Bucklin BA, Hawkins JL, Anderson JR, Ullrich FA. Obstetric anesthesia workforce survey: twenty-year update. Anesthesiol. 2005;103(3):645-53.

2. Mercier FJ, Bonnet MP, Dorie A, Moufouki M, Banu F, Hanaf A, et al. Spinal anaesthesia for caesarean section: fluid loading, vasopressors and hypotension. Ann Fr Anesth Rèanimation. 2007;26(7-8):688-93.

3. Holmes F. Spinal analgesia and caesarean section; maternal mortality. J Obstet Gynaecol $\mathrm{Br}$ Emp. 1957;64(2):229-32.

4. Lees MM, Scott DB, Kerr MG, Taylor SH. The circulatory effects of recumbent postural change in late pregnancy. Clin Sci. 1967;32(3):453-65.

5. Marx GF. Supine hypotension syndrome during cesarean section. JAMA. 1969;207(10):1903-5.

6. Reidy J, Douglas J. Vasopressors in obstetrics. Anesthesiol Clin. 2008;26(1):75-88.

7. Westfall TC, Westfall DP. Adrenergic agonists and antagonists. In: Goodman and Gilman's: The Pharmacological Basis of Therapeutics. $11^{\text {th }}$ ed. New York: McGraw Hill; 2006; 237-95.

8. Sayyid SM, Taha SK, Kanazi GE, Aouad MT. A randomized controlled trial of variable rate phenylephrine infusion with rescue phenylephrine boluses versus rescue boluses alone on physician interventions during spinal anesthesia for elective cesarean delivery. Anesth Analg. 2014;118(3):611-8.

9. Allen TK, George RB, White WD, Muir HA, Habib AS. A double-blind, placebo-controlled trial of four fixed rate infusion regimens of phenylephrine for hemodynamic support during spinal anesthesia for cesarean delivery. Anes Analg. 2010;111(5):1221-9.

10. Doherty A, Ohashi Y, Downey K, Carvalho JCA. Phenylephrine infusion versus bolus regimens during cesarean delivery under spinal anesthesia: a doubleblind randomized clinical trial to assess hemodynamic changes. Anes Analg. 2012;115(6):1343-50.

11. Stewart A, Fernando R, Columb M. Can phenylephrine infusions cause reactive hypertension during elective caesarean section. Int $\mathrm{J}$ Obstet Anesth. 2011;20(S7).

12. Stewart A, Fernando R, McDonald S, Hignett R, Jones T, Columb M. The dose-dependent effects of phenylephrine for elective cesarean delivery under spinal anesthesia. Anes Analg. 2010;111(5):1230-7.

Cite this article as: Masood A, Rasool A, Mir AH, Neesa W, Farooqi A. A prospective observational study involving three fixed infusion regimens of phenylephrine for hemodynamic support during spinal anaesthesia for caesarian delivery. Int J Reprod Contracept Obstet Gynecol 2019;8:2293-301. 